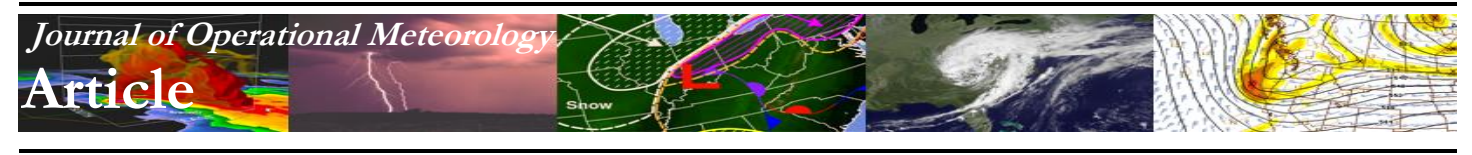

\title{
Usage of Color Scales on Radar Maps
}

\author{
BRITTNEY BRYANT, MATTHEW HOLINER, RACHAEL KROOT, KATHLEEN SHERMAN-MORRIS, WILLIAM B. SMYLIE, \\ LISA STRYJEWSKI, MEAGHAN THOMAS, and CHRISTOPHER I. WILLIAMS \\ Mississippi State University, Mississippi State, Mississippi
}

(Manuscript received 3 October 2013; review completed 14 April 2014)

\begin{abstract}
The visualization of rainfall rates and amounts using colored weather maps has become very common and is crucial for communicating weather information to the public. Little research has been done to investigate which color scales lead to the best understanding of a weather map; however, research has been performed on the general use of color and the theory behind it. Applying color theory specifically to weather maps, we designed this project to see if there was a statistically significant difference in an individual's interpretation of weather data presented in two different color scales. We used a radar map and a storm-total precipitation map, each presented in both a rainbow scale and a monochromatic green scale, for a total of four images. A survey based on these images was distributed online to students at Mississippi State University. After analyzing the results, we found that people who received the radar image with the green scale were more likely to answer questions associated with that image correctly. However, there was no significant difference in accuracy between the two color scales on the storm-total precipitation map. The radar findings align well with what previous color-theory literature suggested; a monochromatic scale is more intuitive to understand than a rainbow scale. This research can be used to help meteorologists better convey weather information in a more understandable way to the general public.
\end{abstract}

\section{Introduction}

Meteorologists use various types of maps and visual displays to communicate forecast information, often without critically examining the most effective way to display the information. The weather maps most widely used to communicate to the public contain a "rainbow" color scale that typically includes some ordering of violet, blue, green, yellow, orange, and red hues. The reason for the prominence of the rainbow scale is not entirely known; however, early adoption by physicists - followed by resistance to change- has been cited (Borland and Taylor 2007). That this color scheme was the default in eight out of nine visualization toolkits studied by Borland and Taylor (2007) helps to affirm its prominence. The rainbow color scale has become so entrenched that it even has been associated with perceived scientific authenticity among the public (Phipps and Rowe 2010).

Researchers, however, have identified many problems with the rainbow color scheme. The rainbow scale does not have an inherent perceptual order (Monmonier 1991; Breslow et al. 2009), meaning it is something we learn, and is not intuitive (Borland and Tay- lor 2007; Silva et al. 2007, 2011). For example, Borland and Taylor (2007) found that if given a series of colored paint chips to order, individuals will not rank them consistently. Significant differences in the way Chinese and American participants ranked several colors also illustrated that the way we order colors is learned (Lesch et al. 2009). When rating the level of risk associated with a series of colors, participants sometimes switched blue and green or yellow and orange (Mayhorn et al. 2004). Without an intuitive perceptual order, participants must depend on a legend to compare locations (Breslow et al. 2009). A related issue with the rainbow map involves its end and middle points. Red and violet are very similar, yet are often opposite ends of the color scale (Silva et al. 2007, 2011). Red and violet also are not intuitively ranked, so there is no natural reason one should be valued higher or lower than the other (Light and Bartlein 2004). Another issue arises when yellow is located on the middle of the scale. As the brightest and most vibrant color, yellow also is the most attention-getting [American Meteorological Society (AMS) 1993; Silva et al. 2007; Phipps and Rowe 2010]. Because of this 
nature, yellow is best used to emphasize diverging values (Light and Bartlein 2004), which often is not the case in familiar uses of the rainbow scale. Cleveland and McGill (1983) found that using an inappropriate color scheme for a particular graphic can lead to optical illusions. Simultaneous contrast is one illusion where colors are perceived differently based on which color is most proximal to them (Slocum 1999). Even if all of the colors are clearly separated and visible, some viewers may not connect the colors with the correct level of intensity (Borland and Taylor 2007). Having multiple colors means that viewers see a sharp and potentially extreme change from one color to another-such as a change from green to yellow-when in fact the values may have shifted only slightly (Borland and Taylor 2007). Additionally, approximately $8 \%$ of the United States population is color-blind (AMS 1993; Heitgerd et al. 2008). In one study, participants with red-green color-blindness took longer to respond to the graphics utilizing the rainbow color scheme (Olson and Brewer 1997).

To acknowledge the importance of proper color selection, an AMS subcommittee for color guidelines was formed at the 6th International Conference on Interactive Information Processing Systems (IIPS). The committee made recommendations for color usage to depict 21 point, line, area, and map features commonly used in meteorology (AMS 1993). Despite creation of these guidelines in the mid 1990s, little research has been conducted on the use of color in weather graphics. In fact, O'Hare and Stenhouse (2009, p. 690) stated that the effectiveness of weather displays, in general, "remains almost entirely unstudied." Meteorologists may glean a better understanding of the impact of color on effective visual communication by reviewing work in other fields.

There is a wide level of interdisciplinary agreement on the best type of color scale to depict certain types of variables. Color properties such as hue, which refers to what we commonly call color, and the lightness or darkness of a color, are best used to illustrate different types of data. Multi-hued scales with no apparent color ordering are useful for nominal-level or categorical data where colors indicate qualitatively different groups or categories (Hoffman et al. 1993; Silva et al. 2007, 2011; Severtson and Vatovec 2012). Quantitative variables are best depicted by single-hued scales with varying levels of luminance or lightness to indicate levels of intensity or amount (Monmonier 1991; Brewer 1994; Light and Bartlein 2004; Kelleher and Wagener 2011). Varying the luminance of a color does not introduce optical illusions in the way that varying hue can (Zeileis et al. 2009). Quantitative variables should correspond to variations of a single color through a direct mathematical relationship where the color property varies according to the measured variable (Hoffman et al. 1993). "Light is less, dark is more" is a strong convention in map-making and visualization (e.g., Mersey 1990; Garlandini and Fabrikant 2009). Therefore, lighter shades of a color should typically represent less intense or lower amounts of a variable while darker shades of that color should represent more, or more intense, quantities of it. The use of a monochromatic color scale can lead to faster processing of complex maps (Hegarty 2012). This is especially true when the task involves a direct comparison (Breslow et al. 2009).

Other work has stressed the importance of considering cultural connotations. For example, people associate green with "safe" and red with "danger" because they are instinctively familiar with these relationships (Hoffman et al. 1993). Other conventions include red with heat, blue with water, or green with vegetation (Monmonier 1991). Many of these common connotations were reflected in the IIPS subcommittee's guidelines for use of color to depict weather symbols (AMS 1993); one such recommendation was the use of green to indicate rain. Selecting colors for weather maps that already have strong cultural connotations may help to improve communication through reducing the cognitive load required to process the image (Silva et al. 2007, 2011).

Several factors also may interact with color to influence a person's comprehension of weather maps, including whether or not a person has a meteorological background (Fabrikant et al. 2010). In a study conducted by Fabrikant et al. (2010), the colors on the weather map distracted viewers who were without any meteorological background. However, viewers with meteorological knowledge were better able to decipher the maps. This distraction arises from different processing strategies between novices and experts. Novices tend to use a "bottom-up" strategy where their perception is guided by the most salient map features, while experts are more likely to employ a "top-down" strategy in which their knowledge guides where they look on a map (Allen et al. 2006; Fabrikant et al. 2010; Hegarty et al. 2010; Meyer et al. 2010; Severtson and Vatovec 2012). Ideally, the most salient features on a map will be the same features that are most important to one's understanding of it (Fabrikant et al. 2010; Healey and Enns 2012). 
Using multiple colors also has its advantages. For instance, an individual can distinguish more different hues of color than shades of one color (Mersey 1990). Between four and eight colors are recommended on a map to provide the greatest amount of visual distinction among them (AMS 1993). With this in mind, the IIPS subcommittee on color guidelines did recommend a rainbow scale with light blue, green, yellow, orange, light red, and red for use on conventional radar imagery. Last, Borland and Taylor (2007) cautioned that there is no one color scheme that will be best for weather maps in all circumstances.

To confront the potential difficulty associated with comprehending information on rainbow color maps, we designed this study to explore other color options. The primary goal was to determine if the use of multiple colors leads to less understanding or lower perceived ease of use on radar images than the use of varying shades of one color. We expected to find that weather maps created using the green color scalewhich is recommended to represent rain because of existing connotations - would be easier for viewers to understand overall. The results, discussed below, help provide a better understanding as to how the designs of weather imagery with respect to color scale can influence comprehension.

\section{Data collection and methods}

In order to determine which color scale leads to the greatest comprehension of weather information, we created maps for testing purposes. Based on the past research mentioned above, we chose to compare the typical rainbow color scale with the monochromatic green scale. We specifically chose green because it is commonly used to represent light precipitation on radar maps; therefore, people already should associate it with rainfall events.

Two types of color-dependent radar-based precipitation maps that are commonly shown to the public are base reflectivity (hereby referred to as radar) and storm-total precipitation. To determine if one color scale is better suited for one type of map or the other, we started with separate radar and storm-total precipitation maps. These images were produced from screen shots of GRlevel3 (which is a viewer for weather radar data; www.grlevelx.com), and represent two separate rainfall events that occurred in the Golden Triangle area of east-central Mississippi. Both of the original images utilized the standard rainbow color scale and were cropped to focus on the Golden Triangle area.
We then altered the images to create monochromatic, green, color-scale versions of the same maps. This process resulted in a total of four maps (Figs. 1-4); a rainbow radar map, a green radar map, a rainbow storm-total precipitation map, and a green storm-total precipitation map.

Once the image alterations were completed, and upon receiving approval to conduct human-subjects research from Mississippi State University's Institutional Review Board, an online survey was created using SurveyMonkey (www.surveymonkey.com). Target participants for the survey consisted of undergraduate and graduate students at Mississippi State University. We contacted professors in the College of Arts and Sciences, the College of Business, and the College of Engineering for permission to recruit their students for the survey. Professors who granted permission either emailed their students a link to the survey or allowed the authors to come into their class, briefly explain the survey, and distribute slips of paper with the link to the survey. Some professors offered their students extra credit for taking the survey to encourage participation. In total, 2083 students were contacted; 645 took the survey, resulting in a $31 \%$ response rate. This is a conservative estimate because some students could have been absent on days that we recruited, and our recruitment total came from the complete class rosters. Of the 645 students who took the survey, 600 responded within the deadline for our statistical analysis.

The survey included three main parts: (1) questions about the respondents, (2) questions designed to measure their understanding, and (3) questions about their opinions of the graphics. The first part was designed to determine if one group of people understood or preferred one type of color scale over the other. In addition to asking standard questions about gender and class year, participants were asked about their past weather experience. Specifically, respondents reported their primary source of weather information, how frequently they obtain weather forecasts, and whether they had ever taken a course that covered meteorological topics. Because the interpretation of colors was so crucial, a color-blindness test was included in the first part of the survey. This allowed for testing to determine if color-blindness affected understanding of a map or if one scale is better suited for people with color-blindness.

Once participants completed the demographic and background questions, the survey progressed to the weather maps. To test understanding, letters (A, B, C and $\mathrm{D})$ were strategically placed at different locations 


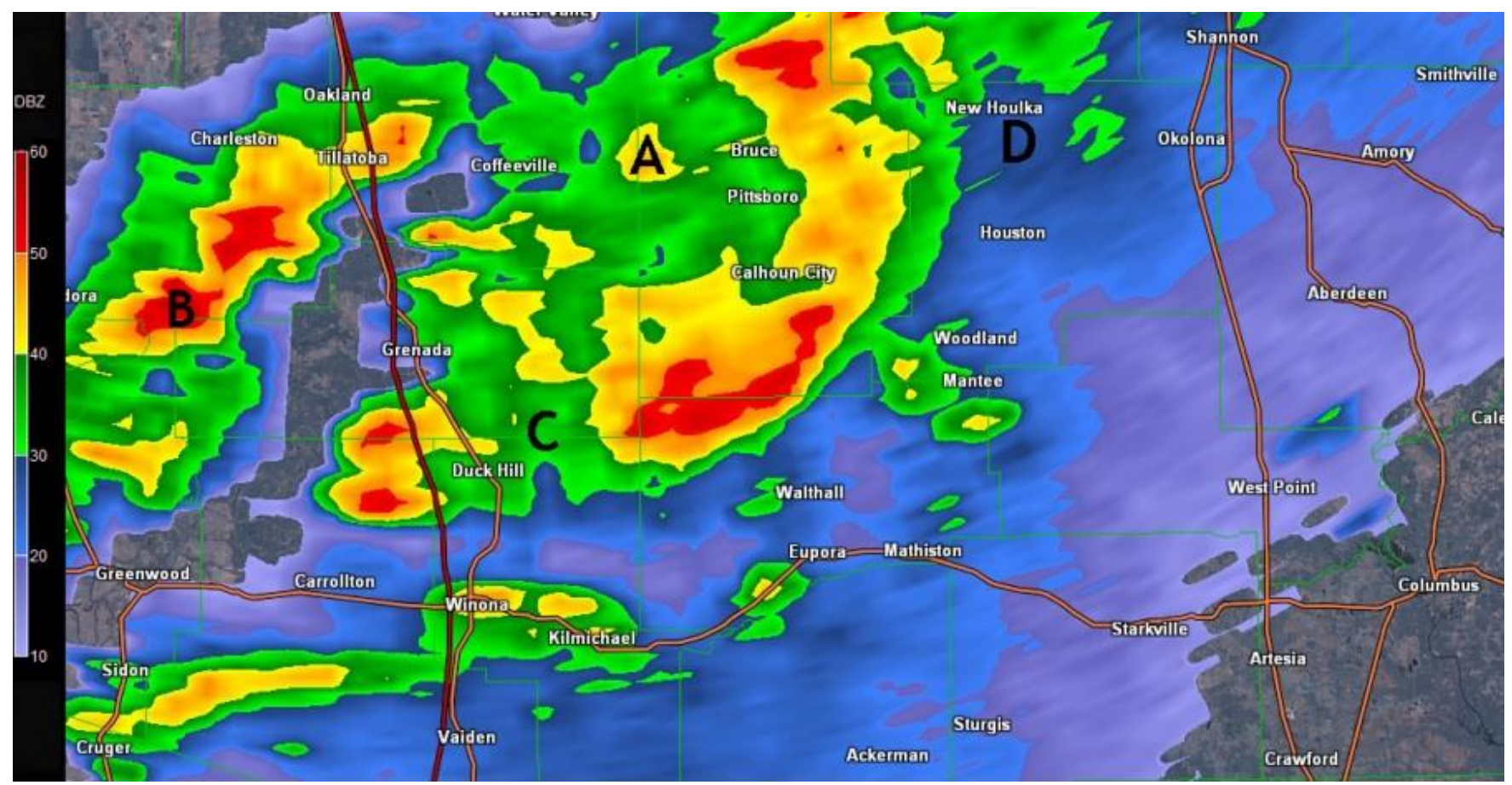

Figure 1. Radar base-reflectivity rainbow map valid 0353 UTC 17 October 2012 . The area shown is approximately $100 \mathrm{~km} \times 180 \mathrm{~km}$. A, $\mathrm{B}, \mathrm{C}$, and D refer to locations of varying intensity. Click image for an external version; this applies to all figures hereafter.

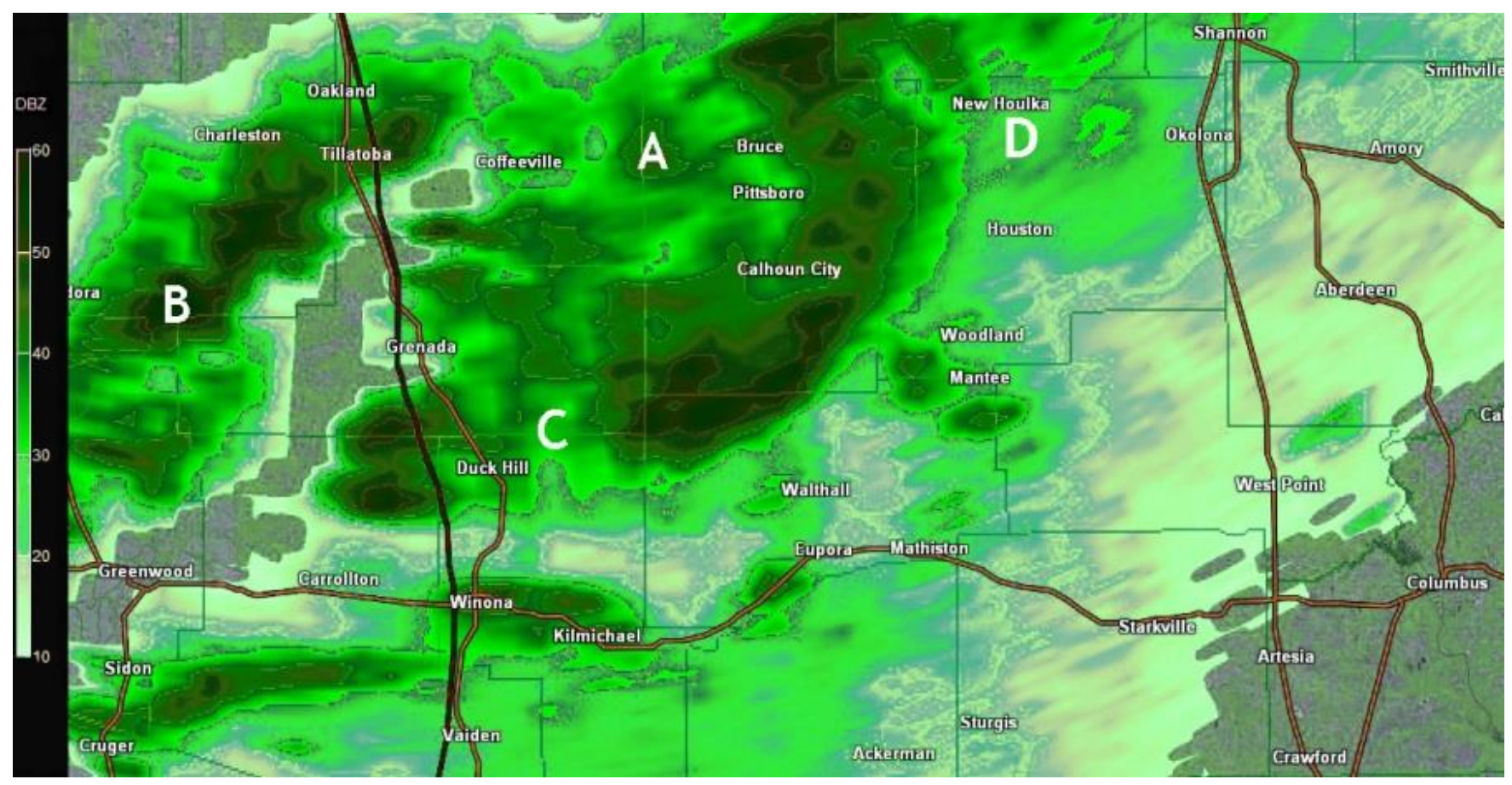

Figure 2. Same as Fig. 1 but for a green map.

on the maps to represent varying amounts of rainfall intensity and accumulation. While the letter placement varied between the radar and storm-total precipitation maps, both the rainbow and the green versions of each map highlighted the same points. SurveyMonkey was configured to randomly assign one of the radar maps (rainbow or green) and one of the storm-total precipitation maps (rainbow or green) to each participant. 


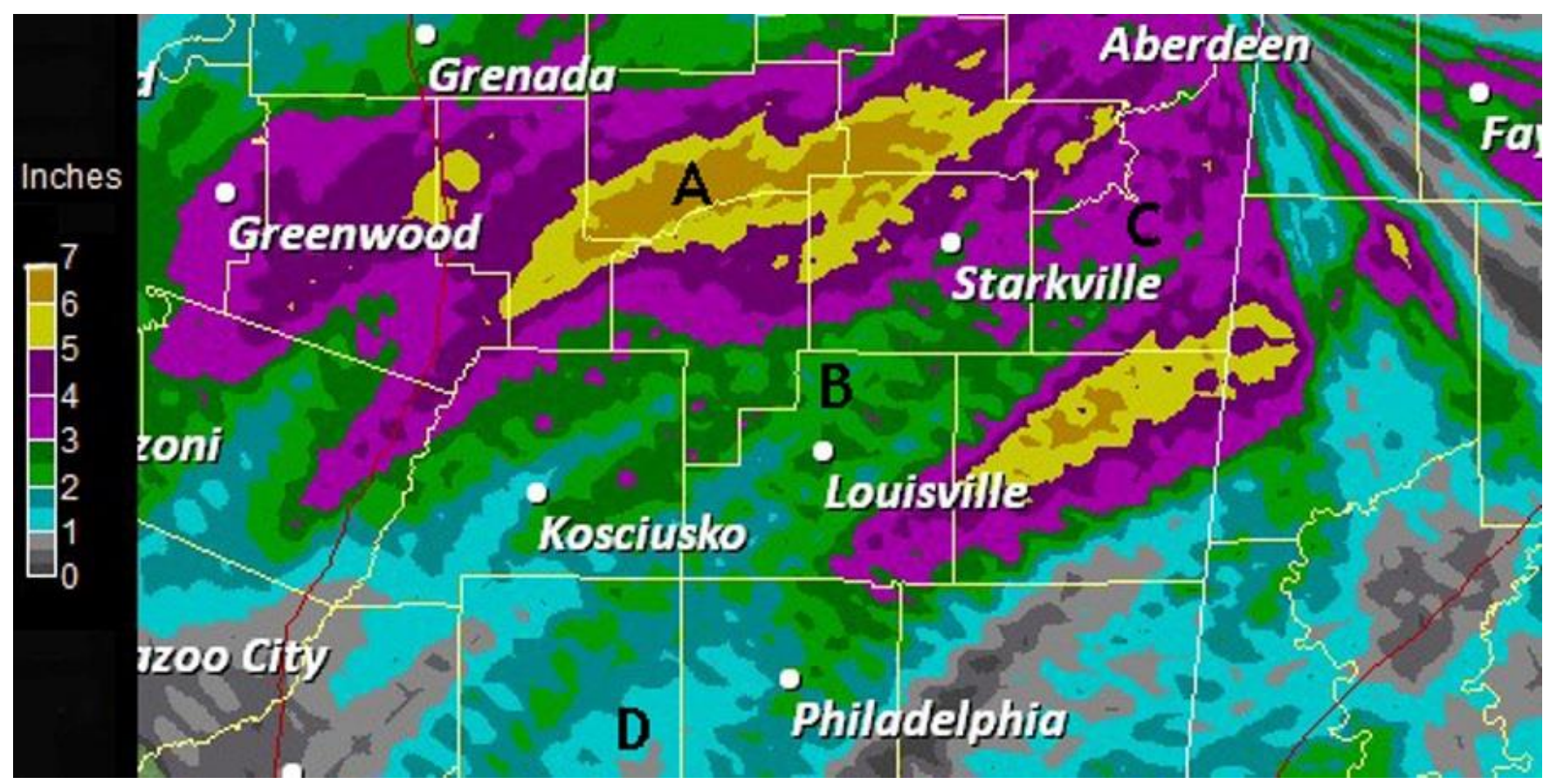

Figure 3. Storm-total precipitation rainbow map valid 0353 UTC 17 October 2012 . The area shown is approximately $250 \mathrm{~km} \times 100 \mathrm{~km}$.

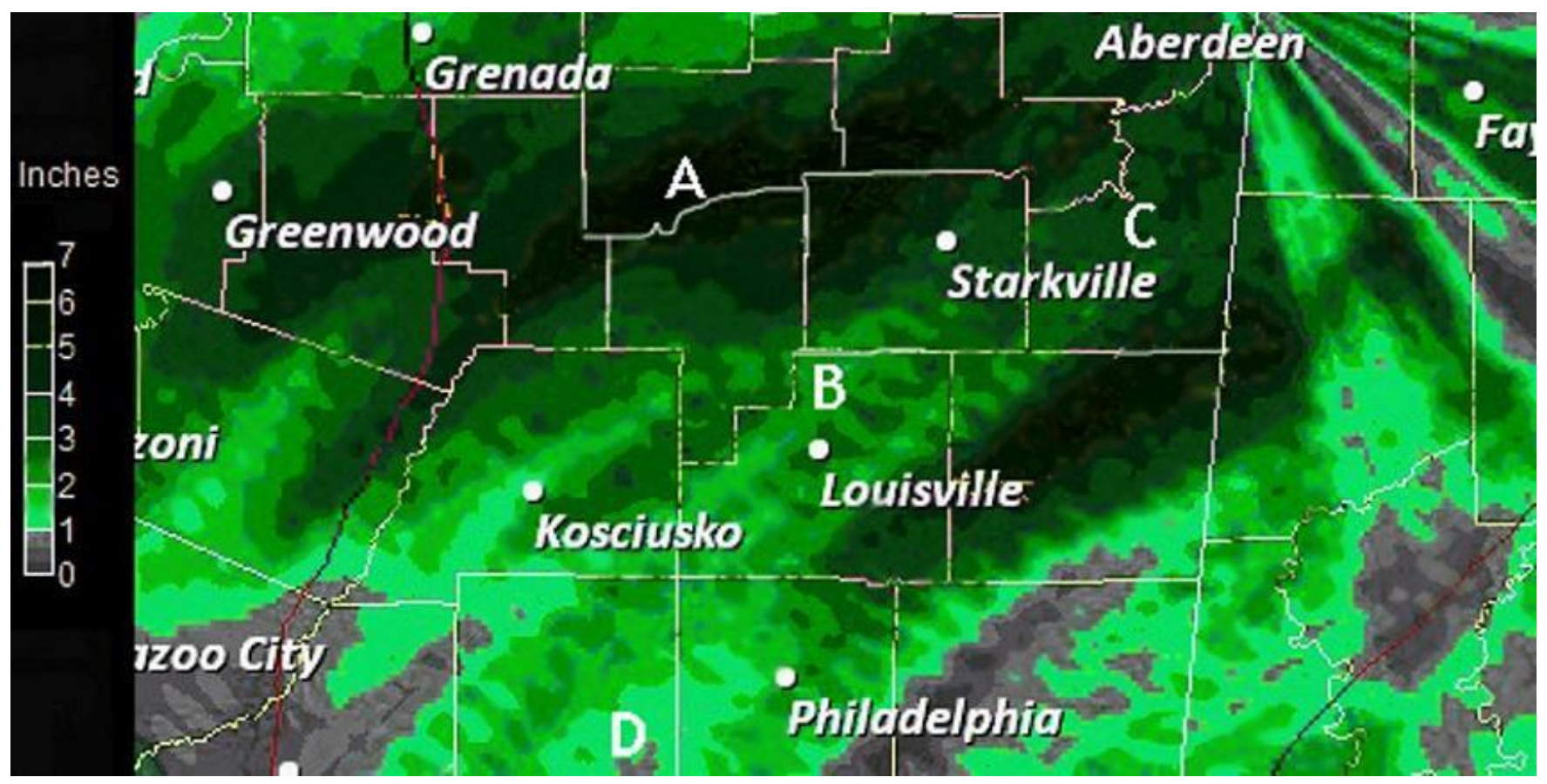

Figure 4. Same as Fig. 3 but for a green map.

These assignments were independent from one another, meaning everyone had the same probability of getting two rainbow maps, two green maps, or one of each. Participants then answered three questions per map to test their understanding. The first question asked participants to identify the letter at which the heaviest precipitation occurred or was occurring. The second question asked at which letter the lightest precipitation occurred or was occurring. The third question asked participants to identify which of two marked locations experienced or was experiencing the greatest rainfall. Participants did not receive any infor- 
mation about the image, or what it displayed, other than that it was a radar image.

Along with testing participants' understanding of the maps, we also wanted to collect their opinions on the maps' appearances. When people typically look at a weather map, it is not in a survey/test environment; they only look at the weather map when it is convenient for them. Hoffman et al. (1993) stated that while viewers can easily pick out a visually displeasing map, they have a difficult time deciding on a map with an attractive color scheme. To gather these opinions, we asked participants four additional questions for each of the two maps they observed. The first question asked participants to rate on a scale from one to five how easy it was to understand the map, with five being the easiest. The second question asked if the map should or should not be used on television. The third question was an open response and asked participants what they would change, if anything, to make the map easier to understand. The fourth question asked if showing more or fewer colors would make the map easier to understand, or if the current amount of colors was adequate.

\section{Results and analysis}

Of the 600 students who participated in the survey prior to the deadline, males represented a slight majority $(53.7 \%)$, and class year was nearly equally split among freshman, sophomore, junior, and senior. Graduate students accounted for only 5.2\% of the sample. Only $11.8 \%$ had taken any classes that covered meteorological topics. A small percentage did not answer one or both color-blindness questions correctly $(7.8 \%$ and $4.5 \%$, respectively). The survey led to a variety of interesting and statistically significant results, as discussed below. Statistical calculations were performed with R (www.r-project.org), except the Mann-Whitney $\mathrm{U}$ non-parametric comparison was done with IBM SPSS (www-01.ibm.com/software/analytics/spss).

\section{a. Overall accuracy}

Participants answered three questions on both the radar map and the storm-total precipitation map and were given a score for accuracy. If the participant answered all three correct, the score was a three. If he/she answered two out of three correct the score was a two, and so on. Figure 5 and Table 1 show accuracy grouped by color scale.

Next, we fit two cumulative logit models with one for the radar image and one for the storm-total precip- itation image. A cumulative logit model describes the probability that a response falls in a certain group (in this case, groups based on number of total correct responses). This particular model is appropriate when the response variable is ordinal. In our case, our response variable is the number of correct responses (out of three). We have $J=3$ groups. The cumulative probability for $Y$ is the probability that $Y$ is equal to or less than a value. For outcome $J$, the cumulative probability is $\mathrm{P}(Y \leq J)=1+\ldots+j ; j=1, \ldots, J$. For our purposes, $\mathrm{P}(Y \leq 3)=$ probability that a participant answers three or fewer questions correctly (this is necessarily = 1). $\mathrm{P}(Y \leq 2)=$ probability that a participant answers two or fewer questions correctly. $\mathrm{P}(Y \leq 1)=$ probability that a participant answers just one question correctly. ${ }^{1}$

The radar results reveal that if a person saw a green radar image there is an $86 \%$ chance they would answer all three questions correctly. On the other hand, if a person saw a rainbow radar image they had a $73 \%$ chance of answering all three questions correctly. To check the model fit, we used the deviance statistic $G^{2}$. Because the $p$ value associated with $G^{2}$ in each model is significant, we can conclude that the models fit adequately. The accuracy results for answering three questions correctly about the storm-total precipitation image followed the same pattern as the radar image; however, the difference was not statistically significant.

Table 1. Frequency table of accuracy (see section 3a) for the radar image (top) and the storm-total precipitation image (bottom).

\begin{tabular}{|c|c|c|c|}
\hline \multicolumn{4}{|c|}{ Radar Image } \\
\hline & \multicolumn{3}{|c|}{ Accuracy } \\
\hline Radar Type & $\mathbf{1}$ & $\mathbf{2}$ & $\mathbf{3}$ \\
\hline Green & 4 & 37 & 243 \\
\hline Rainbow & 15 & 57 & 197 \\
\hline
\end{tabular}

\begin{tabular}{|c|c|c|c|}
\hline \multicolumn{4}{|c|}{ Storm-Total Image } \\
\hline & \multicolumn{3}{|c|}{ Accuracy } \\
\hline Storm-Total Type & $\mathbf{1}$ & $\mathbf{2}$ & $\mathbf{3}$ \\
\hline Green & 3 & 19 & 253 \\
\hline Rainbow & 9 & 18 & 252 \\
\hline
\end{tabular}

Significance was determined by a test for independence that tests the null hypothesis of $\mathrm{H}_{0}: \beta=0$ versus the alternative hypothesis of $\mathrm{H}_{\mathrm{A}}: \beta \neq 0$. The Wald test

\footnotetext{
1 There were nine participants that answered all three questions incorrectly that yielded a score of zero. However, we felt justified in removing these nine from this analysis because we found that these participants answered all three questions incorrectly on the storm-total image as well. Thus, our model does not account for $\mathrm{P}$ $(Y=0)$.
} 


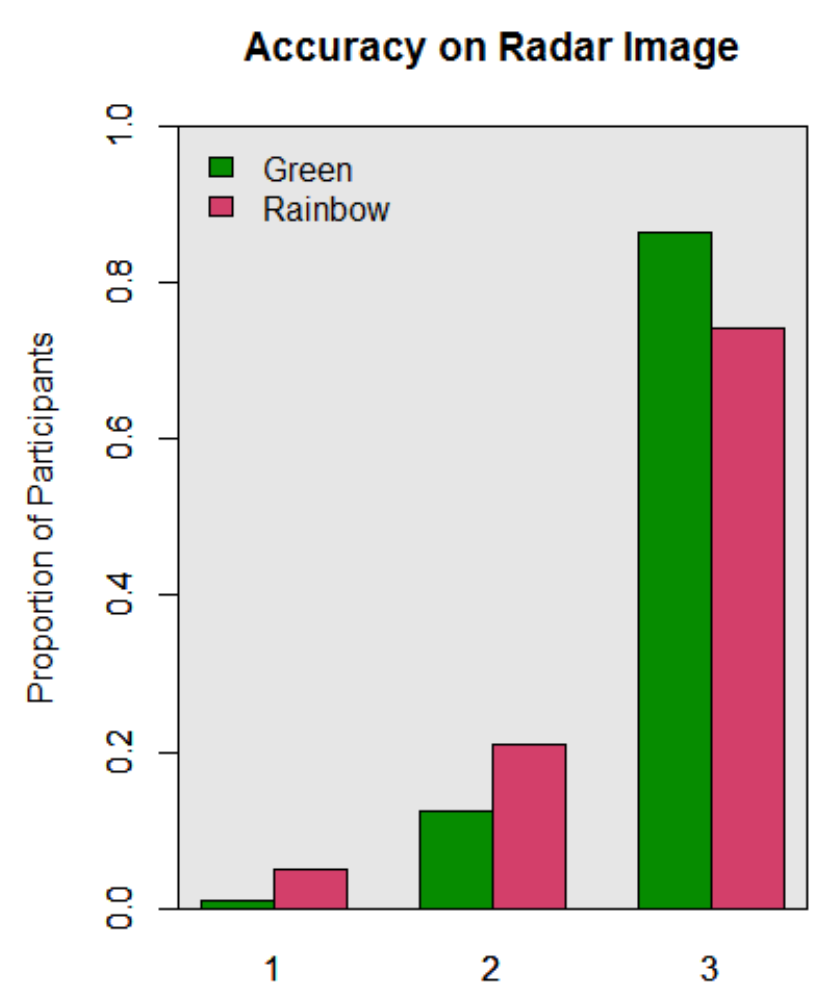

Number Correct

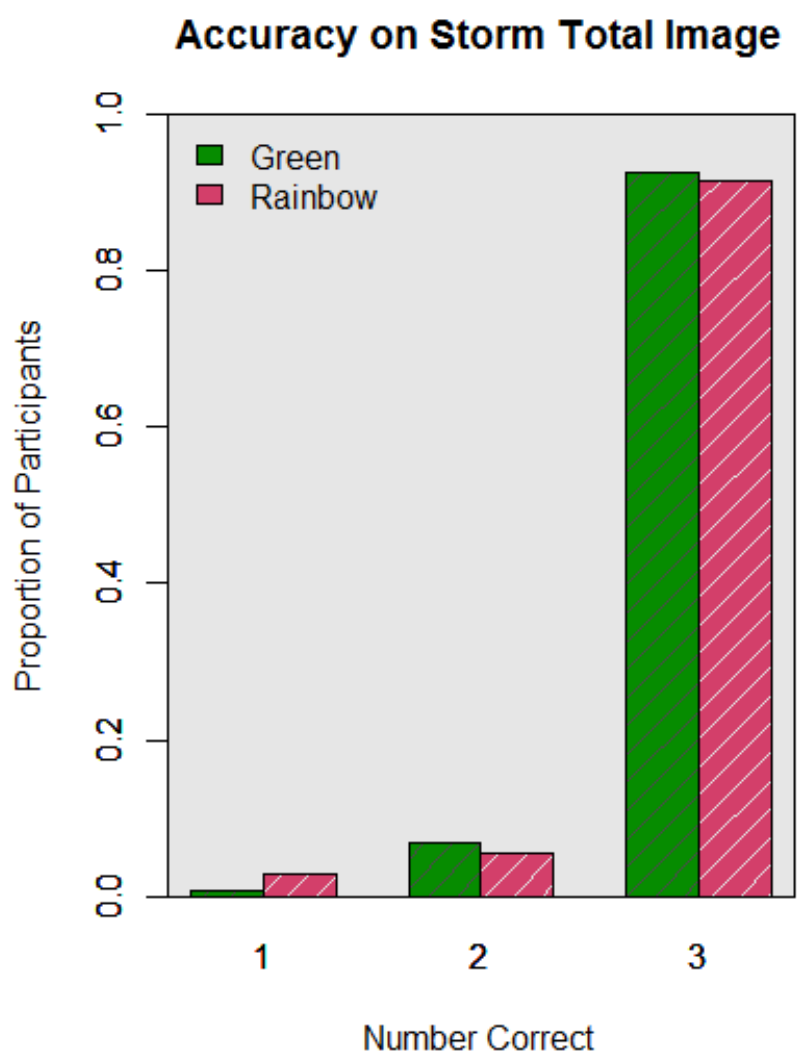




\section{Percentage Correct}

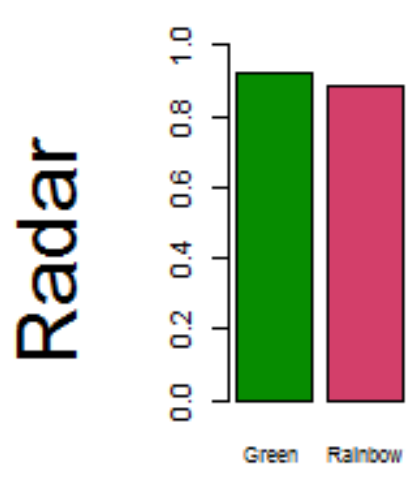

Q1
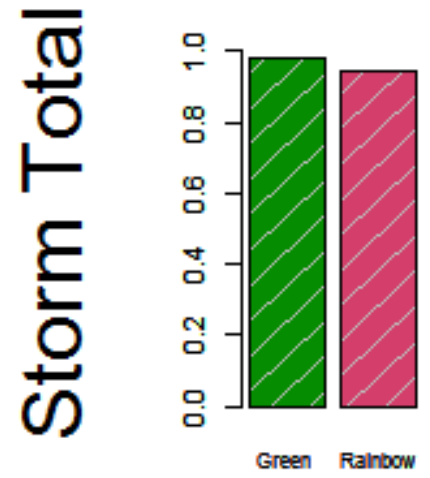

Q1

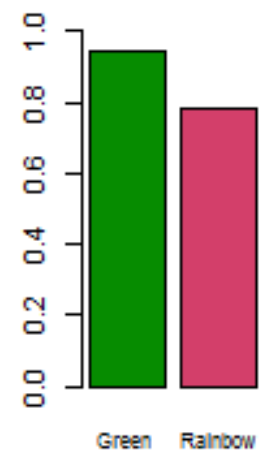

Q2

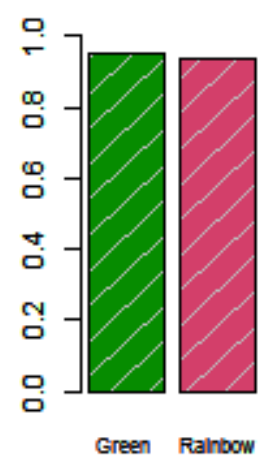

Q2

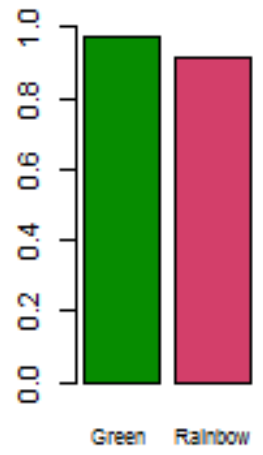

Q3

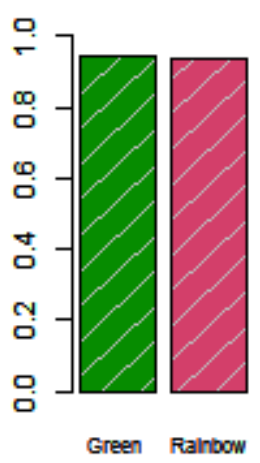

Q3

Figure 6. Bar plots of percentage accuracy for each question for each of the four images in Figs. 1-4. The total, $N$, for each question/image pair ranges from 279 to 290 . Refer to section 2 for the questions.

higher scores for both groups and scores for those participants who had taken meteorology courses were higher than those who had not. The accuracy of participants with meteorology backgrounds who received the green image was higher than those who received the rainbow image, but this difference only approached significance $(p=0.06)$. The higher level of accuracy among respondents with no meteorology background for those who viewed the green image was significant $(p=0.00)$. This may suggest that individuals with less experience viewing radar imagery perform better when shown an image that is more intuitive. The comparison for those who obtain a forecast once or less per month also would support this suggestion. This conclusion also is in line with research that demonstrates different map viewing strategies between experts and non-experts where experts' attention is more driven by content while non-experts are influenced to a greater extent by map design elements (Allen et al. 2006; Fabrikant et al. 2010; Hegarty et al. 2010; Meyer et al. 2010; Severtson and Vatovec 2012). The rainbow images led to lower accuracy rates among respondents who did not answer one or both color-blindness questions correctly; however, this represented too small a portion of the sample to test for significance.

\section{c. Opinions about the images}

Participants rated the green radar image slightly easier to interpret than the rainbow image, but this difference was not statistically significant. The stormtotal images were rated approximately the same. Participants also answered the question, "What would you change, if anything, to make this map easier to under- 
stand?" on both the radar and storm-total precipitation images. This question was open-ended. Figure 7 lists some common responses. For the radar image, some responses are very much in opposition. For example, respondents who received the rainbow image suggested fewer colors while some who had received the green image suggested more colors. For both radar and storm-total precipitation images, respondents receiving green more frequently suggested using additional colors. Respondents who received the rainbow images offered a greater range of suggestions on how to make the colors better. Several responses indicated that a scale should be provided. It should be noted that the scales were included, although the reflectivity units (dBZ) may not have been very meaningful for all respondents. Respondents were not questioned regarding their understanding of reflectivity or its units.

\section{Discussion}

We expected respondents who received the green images to have higher accuracy on the understanding questions than respondents who received the rainbow images. For the radar image, we found that people who got the green map (see Fig. 2) were more likely to answer all three questions correctly. Other more focused statistical analyses also were performed for the demographic questions. Statistically different accuracy results were found for all image comparisons except among respondents with a meteorology background. Green radar maps most frequently resulted in more accurate answers.

Past color-theory research has shown that rainbow scales are sometimes difficult to understand. The radar findings of this study align with previous color researchers' findings in that participants of this survey clearly understood the green color scale better than the rainbow scale. However, opinion comments showed no statistically significant preference for one color scale over the other; therefore, when choosing a scale for a weather map, the primary objective should be to maximize understanding. Although the results did in fact support the expectation that there would be a difference, future research in this area should aspire to widen the subject pool beyond the college campus to better represent the public. Examining responses among the public also would help to tease out the influence of experience with obtaining weather information on understanding. Furthermore, maps used in future studies should be presented to participants without a color scale for reference. There was a legend present in our maps, which may have made it easier for participants to interpret the scale. They were not required to self-impose an order of the colors on the rainbow image because the order was already defined. If possible, it also might be beneficial to conduct any future surveys with a timer, because we were unable to test how long it took viewers to answer the questions. If the green maps take viewers longer to interpret, television stations with a limited timeframe may be less likely to utilize that scale regardless of its understanding levels. Additional monochromatic color scales also should be tested to see if other colors will lead to better understanding than green. Finally, a future study also should consider interaction and learning effects. This could be addressed through a withinsubjects design in which all participants see all image types in varied order. Because little literature was found in the area of study on which this project was focused, these results can aid both media and private sector meteorologists in developing a better way to display weather information.

\section{Conclusion}

After surveying 600 Mississippi State University students - both undergraduate and graduate - it was found that participants did in fact have higher accuracy on the green images than the rainbow images, particularly with the base-reflectivity radar map. This supports our hypothesis that images with a monochromatic green scale would be better understood than rainbow images. With the knowledge from this study, meteorologists in the future may choose to display weather information using a monochromatic color scale. As acknowledged earlier, different color scales are best suited to different tasks. The monochromatic scale in this study agreed with past research that it helped participants to judge different quantities or intensities of rainfall. All users of radar maps may not have the same goal in viewing the map, so it is possible that other color schemes would be better suited for tasks not explored by this study.

Aspects of color-theory research have been performed in fields such as psychology and engineering, but only a limited amount has been performed specifically in meteorology. A color scale can be applied to any meteorological variable, but its ability to be understood by the general public is an area that meteorologists struggle with to know which scale leads to most accurate interpretation among users. Whereas the study sample for this research is limited to students 


\section{Storm Total}

Rainbow Colors that flow better instead of coming from all over the color wheel.
The purple made me second guess myself and it wasn't until l looked at the key that I knew yellow
was worse than purple.
Colors are not universal. Nobody knows what they are unless you study the scale
The colors should be in "colorsequential"? order
Have a key at the bottom letting viewers know which one is worse, purple or yellow.
Green Using different shades of one color makes it harder to understand.
The green. It would have been better if there was another color added to the map.
Use more colors. The shades of green sort of blend together.
Don't just change the shade of color, add more color.
Use some colors other than green so people can more easily see differences between values.
Rainbow
if there were fewer colors
actually indicating what the colors mean
inform the viewer if blue is snow or rainfall
Tell what each color means and what it entails.
Explain what the colors mean
Tell what each color represents.
More Colors
Use different colors! It is very challenging to tell the differnece between light and dark green.
More distinct color variations
Put heavy participation in yellow or red
Hue colors. Not every in green color.

Figure 7. Comments from participants. Refer to section $3 \mathrm{c}$ for a discussion.

from Mississippi State University and may not be generalizable to the public, it is a reference point for future research. A nearby National Weather Service Weather Forecast Office (WFO) has already expressed interest in conducting further studies expanding the ideas behind this paper to their warning area. In that respect, some authors of this paper are (at the time of this paper) assisting members of this WFO in developing maps to test variables such as snowfall totals, apparent temperature, and watches and warnings. The goal is to formulate a survey in which respondents will answer questions about two different color scales with the goal to develop and implement a color scheme that maximizes understanding among WFO website users. Further tests should be performed with additional color palettes and with a wider audience to determine to what extent results will apply to the public. Future research in this field also should examine a color scale that will maximize understanding for the general public but also will be appealing.

Acknowledgments. The authors thank Dr. Andrew Mercer (Mississippi State University) for guidance on statis- tical analysis and Renny Vandewege for assistance with radar imagery.

\section{REFERENCES}

Allen, G. L., C. R. M. Cowan, and H. Power, 2006: Acquiring information from simple weather maps: Influences of domain-specific knowledge and general visual-spatial abilities. Learn. Individ. Differ., 16, 337349, CrossRef.

AMS, 1993: Guidelines for using color to depict meteorological information: IIPS subcommittee for color guidelines. Bull. Amer. Meteor. Soc., 74, 1709-1713, CrossRef.

Borland, D., and R. M. Taylor, 2007: Rainbow color map (still) considered harmful. IEEE Comput. Graph., 27, 14-17, CrossRef.

Breslow, L. A., R. M. Ratwani, and J. G. Trafton, 2009: Cognitive models of the influence of color scale on data visualization tasks. Hum. Factors, 51, 321-338, CrossRef.

Brewer, C. A., 1994: Color use guidelines for mapping and visualization. Visualization in Modern Cartography. A. 
M. MacEachren and D. R. F. Taylor, Eds., Elsevier, 123-147, CrossRef.

Cleveland W. S., and R. McGill, 1983: A color-caused optical illusion on a statistical graph. Amer. Stat., 37, 101-105.

Fabrikant, S. I, S. R. Hespanha, and M. Hegarty, 2010: Cognitively inspired and perceptually salient graphic displays for efficient spatial inference making. Ann. Assoc. Amer. Geogr., 100, 13-29, CrossRef.

Garlandini, S., and S. I. Fabrikant, 2009: Evaluating the effectiveness and efficiency of visual variables for geographic information visualization. Proceedings of the Ninth Int. Conf. on Spatial Information Theory, Aber Wrac'h, France, Springer, 195-211. [Available online at geog.ucsb.edu/ sara/html/research/pubs/ garlandini_fabs09.pdf.]

Healey, C. G., and J. T. Enns, 2012: Attention and visual memory in visualization and computer graphics. IEEE T. Vis. Comput. Gr., 18, 1170-1188, CrossRef.

Hegarty, M., cited 2012: Meta-representational competence as an aspect of spatial intelligence. [Available online at mindmodeling.org/cogsci2012/papers/0222/paper0222. pdf.]

M. S. Canham, and S. I. Fabrikant, 2010: Thinking about the weather: How display salience and knowledge affect performance in a graphic inference task. $J$. Exp. Psychol., 36, 37-53, CrossRef.

Heitgerd, J. L., and Coauthors, 2008: Community health status indicators: Adding a geospatial component. Preventing Chronic Disease: Public Health Research, Practice, and Policy, 5 (3), 1-5. [Available online at www.ncbi.nlm.nih.gov/pmc/articles/PMC2483562/pdf/ PCD53A96.pdf.]

Hoffman, R. R., M. Detweiler, J. A. Conway, and K. Lipton, 1993: Some consideration in using color in meteorological displays. Wea. Forecasting, 8, 505-518, CrossRef.

Kelleher. C., and T. Wagener, 2011: Ten guidelines for effective data visualization in scientific publications. Environ. Modell. Softw., 26, 822-827, CrossRef.

Lesch, M. F., P.-L. P. Rau, Z. Zhao, and C. Liu, 2009: A cross-cultural comparison of perceived hazard in response to warning components and configurations: US vs. China. Appl. Ergon., 40, 953-961, CrossRef.

Light, A., and P. J. Bartlein, 2004: The end of the rainbow? Color schemes for improved data graphics. Eos Trans., 85, 385-391, CrossRef.
Mayhorn, C. B., M. S. Wolgarter, and E. F. Shaver, 2004: What does code red mean? Ergonomics in Design, Fall, 12. [Available online at www.hfes.org/Web/Newsroom/ EIDsafetysymbols.pdf.]

Mersey, J. E., 1990: The role of colour scheme and map complexity in chloropleth map communication. Colour and Thematic Map Design, Cartographica Monograph, No. 41, University of Toronto Press, 182.

Meyer, K., T. Rasch, and W. Schnotz, 2010: Effects of animation's speed of presentation on perceptual processing and learning. Learn. Instr., 20, 136-145, CrossRef.

Monmonier, M., 1991: How to Lie With Maps. University of Chicago Press, 176 pp.

O'Hare, D., and N. Stenhouse, 2009: Under the weather: An evaluation of different modes of presenting meteorological information for pilots. Appl. Ergon., 40, 688693, CrossRef.

Olson, J. M., and C. A. Brewer, 1997: An evaluation of color selections to accommodate map users with colorvision impairments. Ann. Assoc. Am. Geogr., 87, 103134, CrossRef.

Phipps, M., and S. Rowe, 2010: Seeing satellite data. Public Underst. Sci., 19, 311-321, CrossRef.

Severtson, D. J., and C. Vatovec, 2012: The theory-based influence of map features on risk beliefs: Self-reports of what is seen and understood for maps depicting an environmental health hazard. J. Health Commun.,17, 836-856, CrossRef.

Silva, S., J. Madeira, and B. S. Santos, 2007: There is more to color scales than meets the eye: A review on the use of color in visualization. Preprints, $11^{\text {th }}$ Int. Conf. on Information Visualization., IEEE Computer Society, Washington, DC, 943-950. [Available online at ieeexplore.ieee.org/xpls/abs_all.jsp?arnumber=4272091 $\& \operatorname{tag}=1]$

, B. S. Santos, and J. Madeira, 2011: Using color in visualization: A survey. Comput. Graph., 35, 320-333, CrossRef.

Slocum, T. A., 1999: Thematic Cartography and Visualization. Prentice Hall, 293 pp.

Zeileis, A., K. Hornik, and P. Murrell, 2009: Escaping RGBland: Selecting colors for statistical graphics. Comput. Stat. Data An., 53, 3259-3270, CrossRef. 